\title{
Pelatihan Prophetic Parenting untuk Menurunkan Stres Pengasuhan pada Ibu dengan Anak Disabilitas Tunanetra
}

\author{
Ridha Habibah', H. Fuad Nashori' ${ }^{2}$, Retno Kumolohadi ${ }^{3}$ \\ 1,2Fakultas Psikologi dan Ilmu Sosial Budaya, Universitas Islam Indonesia, Yogyakarta \\ 1ridhahabibaha@gmail.com, ${ }^{2}$ fuadnashori@uii.ac.id, ${ }^{3}$ retnokumolohadi@uii.ac.id
}

Article History:

Received

2021-11-10

Review

2021-12-11

Revised

2021-12-17

Accepted

2021-12-18

Published

2021-12-28
Abstract. This study aims to determine the effect of prophetic parenting training in reducing parenting stress in mothers with children with disabilities. Parenting stress was measured using the parenting stress scale from Abidin (Ahern, 2004) adapted by Kurniawan (2012) with a total of 36 items and coefficient $\alpha=0.82$. Pretest were done before training, posttest 1 was done after training, and posttest 2 was done two weeks after training. The result of friedman test showed that score of $p=0.043(p<0.05)$. Mann whitney test showed that the score of first posttest with $p=0.054(p>0.05)$ and second posttest with $\mathrm{p}=0.017(\mathrm{p}<0.05)$. Hence, it can be concluded that prophetic parenting training has brought significant effect on the reduction of parenting stress among mothers with child with disabilities (blind) after getting time to practice prophetic parenting. The qualitative analisys also supported the result by showing a positive change experienced in emotional, cognitive, behavioral, and spiritual aspect.

Keywords: prophetic parenting training, parenting stress, chld with disability (blind)

Abstrak. Penelitian ini bertujuan untuk mengetahui pengaruh pelatihan prophetic parenting dalam menurunkan stres pengasuhan pada ibu dengan anak disabilitas (tunanetra). Stres pengasuhan diukur menggunakan skala stres pengasuhan dari Abidin (Ahern, 2004) yang diadaptasi oleh Kurniawan (2012) dengan jumlah aitem sebanyak 36 aitem dengan koefisien $\alpha=0.82$. Prates dilakukan sebelum pelatihan, pascates 1 dilakukan setelah pelatihan, dan pascates 2 dilakukan dua minggu setelah pelatihan. Friedman test menghasilkan signifikansi sebesar $\mathrm{p}=0.043 \quad(\mathrm{p}<0.05)$. Uji mann whitney menunjukkan bahwa pengukuran pascates 1 memiliki nilai $\mathrm{p}=0.054(\mathrm{p}>0.05)$ dan pascates 2 memiliki nilai $\mathrm{p}=0.017(\mathrm{p}<0.05)$. Oleh karena itu dapat disimpulkan bahwa pelatihan prophetic parenting memberikan pengaruh yang signifikan terhadap penurunan stres pengasuhan pada ibu dengan anak disabilitas (tunanetra) setelah mendapatkan waktu untuk mempraktikkan prophetic parenting. Hal tersebut didukung oleh analisis kualitatif yang menunjukkan adanya perubahan positif yang dialami subjek kelompok eksperimen dalam aspek emosi, kognitif, perilaku, dan spiritual.

Kata kunci: pelatihan prophetic parenting, stres pengasuhan, anak disabilitas (tunanetra) 


\section{Pendahuluan}

Salah satu tujuan dari pernikahan adalah untuk mendapatkan keturunan yang sehat dan baik secara jasmani maupun rohani atau dapat dikatakan anak yang normal. Pada kenyataannya harapan tersebut tidak selalu dapat terwujud yakni terdapat orangtua yang diberikan anak-anak dengan kondisi kurang normal atau menyandang disabilitas. Anak disabilitas merupakan yang memiliki keterbatasan fisik, mental, intelektual atau sensorik sehingga memiliki hambatan dalam berinteraksi dengan lingkungan dan masyarakat (Undang-undang Republik indonesia Nomer 35 tahun 2014).

Adapun salah satu ragam dari penyandang disabilitas adalah disabilitas fisik yang terbagi pada penyandang tunanetra, tunarungu, dan tunadaksa. Tunanetra merupakan salah satu macam penyandang disabilitas yang memiliki keterbatasan dari segi penglihatan baik itu tidak dapat melihat sama sekali atau tidak dapat melihat sebagian. Salah satu penelitian menyatakan bahwa orangtua yang memiliki anak disabilitas tunanetra perlu melakukan usaha yang keras dalam merawat, mengasuh, dan mendidik anak (Kamaruddin, 2019). Kaitannya dengan keterbatasan mobilitas pada anak tunanetra sehingga orangtua perlu mendampingi anaknya dalam setiap melakukan aktivitas (Desiningrum, 2016). Penelitian lain menyatakan bahwa dengan adanya tantangan yang besar dalam merawat anak disabilitas tunanetra dapat menjadikan orangtua mengalami stres yang tinggi dan adanya sikap negatif dari masyarakat (Thwala, Ntinda, \& Hlanze, 2015; Omnihara, Marpaung, \& Mirza, 2019).

Peneliti juga mewawancarai dua orangtua dari anak tunanetra. Hasil wawancara terhadap subjek pertama (NR, laki-laki, 43 tahun) adalah peran orangtua dalam menjalankan pengasuhan terkadang mengalami disfungsi misalnya ketika anak mengalami rewel atau melakukan sesuatu hal yang membuat orangtua merasa kesal, respon dari orangtua adalah melakukan pukulan fisik atau berbicara dengan nada yang tinggi. Anak tersebut juga masih berusia 7 tahun sehingga masih sangat membutuhkan pendampingan dalam segala aktivitas kesehariannya. Adapun subjek kedua (IH, wanita, 38 tahun) menyatakan bahwa dirinya sangat sering tidak dapat melakukan aktivitas bagi diri sendiri karena harus mendampingi anaknya setiap waktu. Ditambah dengan peran ayah yang kurang sehingga anak cenderung selalu ingin bersama ibu dalam melakukan segala aktivitas. Subjek juga mengaku merasa khawatir akan masa depan anaknya karena memiliki keterbatasan penglihatan.

Hasil wawancara di atas juga sesuai dengan hasil penelitian dari Uswatunnisa, Brebahama, dan Kinanthi (2018) yang menyatakan bahwa anak yang mengalami 
tunanetra menunjukkan perkembangan yang lebih lambat dibandingkan dengan anak normal seusianya. Hal tersebut berdampak pada keseharian dari keluarga dan menyita waktu keluarga. Selain itu stigma negatif dari masyarakat pun masih sering muncul seperti anggapan bahwa anak tunanetra merupakan hasil dari kutukan karena perbuatan asusila di masa lalu. Anggapan atau stigma negatif tersebut menjadikan keluarga terutama orangtua mengalami stres dan terkadang muncul gejala depresi, serta orangtua mengalami disfungsi dalam menjalankan perannnya dalam pengasuhan anak.

Adanya reaksi emosi negatif dan pengasuhan yang tidak layak merupakan ciri adanya stres pengasuhan yang dialami orangtua. Penelitian lain menemukan bahwa stres pengasuhan berhubungan dengan menurunnya kualitas dan disfungsi interaksi orangtuaanak. Hal itu yang menyebabkan peningkatan perilaku orangtua yang tidak kompeten sehingga membuat memburuknya perkembangan kognitif dan sosial-emosional untuk anak (Quinonez, Keelsc, Jr. Vann, Mclver, Heller, \& Whitt, 2001; Jabbarifar, Ahmady, Sahafian, Samey, \& Soheillipour, 2009).

Merujuk pada beberapa penelitian, Deater-Deckard (1998) diketahui bahwa stres pengasuhan dapat dikurangi melalui terapi, konseling, dan pendidikan kepada orangtua. Sejumlah penelitian telah dilakukan para ahli untuk mengetahui strategi yang efektif dalam meneruskan stress pengasuhan. Penelitian yang dilakukan Rahayu, Ni'matuzzahroh, dan Amalia (2019) menunjukkan bahwa religiusitas berpengaruh terhadap stres pengasuhan. Demikian juga penelitian Kurniawan dan Uyun (2013) juga menunjukkan pengasuhan spiritualitas dapat menurunkan stres pengasuhan. Beberapa penelitian di atas menunjukkan intervensi yang berorientasi pada pandangan Islam dapat membantu penurunan stres pengasuhan.

Upaya untuk mengurangi berbagai kondisi psikologis yang kurang menguntungkan dapat dilakukan dengan intervensi psikologi Islam. Dikatakan oleh Nashori, Diana, dan Hidayat (2020) bahwa intervensi psikologi Islam merupakan pendekatan yang digunakan untuk mengatasi berbagai permasalahan psikologis dengan merujuk pada pandangan dunia Islam. Intervensi psikologi Islam dapat dikelompokkan menjadi dua, yaitu intervensi psikologi Islam orisinal dan intervens psikologi Islam integratif. Merujuk pada pandangan di atas, pelatihan prophetic parenting dapat dikelompokkan sebagai intervensi psikologi Islam orisinal dikarenakan sepenuhnya bersumber dari ajaran Islam. Dibanding intervensi Kurniawan dan Uyun (2013), prophetic parenting secara eksplisit merujuk pada pandangan Islam sebagaimana dirumuskan oleh Suwaid (2010). 
Pelatihan prophetic parenting dalam hal ini dapat meningkatkan keterampilan pengasuhan, lebih lanjut merupakan pengasuhan yang meneladani cara Rosulullah dalam mengasuh anak yang sesuai dengan al-qur'an dan al-hadits dalam membentuk kepribadian anak secara bertahap (Suwaid, 2010). Meneladani Rosul merupakan salah satu jalan untuk menyambungkan hubungan manusia dengan pencipta-Nya dan termasuk bentuk ketaatan pada Allah. Dalam hal ini mengikuti Rosul merupakan sesuatu hal yang diperintahkan oleh-Nya (Edi, 2014).

Menurut Williford, Calkins, dan Keane (2007) serta Hsiao (2017), salah satu faktor stres pengasuhan adalah karakteristik orangtua yang meliputi di antaranya kesejahteraan diri orangtua dan wawasan atau informasi mengenai strategi koping dalam menghadapi stres pengasuhan. Faktor-faktor tersebut yang menjadi sasaran dari aspek-aspek yang tercakup dalam pelatihan prophetic parenting yaitu aspek jiwa, hati, akal, dan jasmani. Berdasarkan pemaparan sebelumnya, tujuan dari penelitian ini adalah adanya perubahan skor stres pengasuhan pada kelompok yang diberikan pelatihan prophetic parenting dibandingkan dengan kelompok yang tidak mendapatkan pelatihan prophetic parenting.

\section{Metode}

Subjek dalam penelitian ini adalah sebanyak tujuh orang ibu yang memiliki beberapa karakteristik yaitu (1) memiliki anak penyandang disabilitas tunanetra, (2) memiliki anak lebih dari satu, (3) beragama islam, dan (4) memiliki skor stres pengasuhan dengan kategori sedang hingga sangat tinggi. Dari tujuh orang tersebut terdapat dua kelompok, yaitu tiga orang pada kelompok eksperimen dan empat orang pada kelompok kontrol. Penelitian ini menggunakan desain non-equivalent pretest postest control group design untuk mengetahui pengaruh suatu perlakuan terhadap kelompok eksperimen (Cook \& Campbell, 1979). Tiga lokasi sekolah dipilih sebagai lokasi penelitian dan untuk mencegah munculnya ancaman validitas internal. SLB A sebagai kelompok eksperimen dan SLB B dan C sebagai kelompok kontrol.

Tabel 1.

Rancangan Penelitian Eksperimen

\begin{tabular}{ccccc}
\hline Kelompok & Prates & Perlakuan & Pascates1 & Pascates2 \\
\hline KE & 01 & $X$ & 02 & 03 \\
KK & 01 & - & 02 & 03 \\
\hline
\end{tabular}

Keterangan:

$\mathrm{KE} \quad=$ Kelompok Perlakuan

$\mathrm{KK} \quad=$ Kelompok Kontrol

$01=$ Pengisian skala stres pengasuhan sebelum perlakuan

$02=$ Pengisian skala stres pengasuhan setelah perlakuan (pascates 1 )

$03=$ = Pengisian skala stres pengasuhan 2 minggu setelah perlakuan (pascates 2 )

$\mathrm{X} \quad=$ Intervensi (Pelatihan Prophetic Parenting) 
Pengumpulan data awal dilakukan melalui wawancara dan observasi terhadap beberapa subjek. Adapun pengambilan data prates dan pascates dilakukan terhadap seluruh subjek penelitian dengan menggunakan skala stres pengasuhan. Skala stres pengasuhan mengacu pada skala dari Abidin yang telah dimodifikasi dan diuji coba oleh Kurniawan (2012) yang terdiri dari 36 aitem dengan koefisien reliabilitas $\alpha=0.82$. Aspekaspek dari stres pengasuhan ada tiga yaitu distress parents, parent-child dysfunctional, dan difficult child (Ahern, 2004).

Intervensi yang diberikan adalah pelatihan prophetic parenting yang mengacu pada modul pelatihan prophetic parenting dari Fitria (2018) yang telah dimodifikasi oleh peneliti. Intervensi dilakukan melalui tahapan persiapan dan pelaksanaan. Tahapan persiapan meliputi dilakukannya professional judgment terhadap modul yang akan digunakan, perizinan pada pihak sekolah, seleksi peserta, fasilitator, dan observer. Setelah tahapan persiapan selesai peneliti melakukan tahapan pelaksanaan yakni dilakukannya pelatihan prophetic parenting sebanyak empat kali pertemuan dengan durasi kurang lebih 2,5 jam dari masing-masing pertemuan. Pada masing-masing pertemuan dipaparkan materi yang berbeda. Materi yang diberikan adalah pengetahuan mengenai memberi keteladanan yang baik, memilih waktu yang tepat untuk memberi pengarahan, bersikap adil terhadap semua anak, menunaikan hak anak, mendoakan anak, dan membantu agar anak berbakti dan taat (Suwaid, 2010). Materi disampaikan dengan metode ceramah, simulasi, dan mengisi lembar kerja. Setiap awal dan akhir pertemuan selalu dilakukan penyegaran materi dengan tujuan subjek penelitian dapat mengingat dan menerapkannya saat melakukan pengasuhan terhadap anak dengan tunanetra.

\section{Hasil}

Hasil dari penelitian ini dilakukan melalui uji hipotesis dengan menggunakan friedman test untuk mengetahui pengaruh pelatihan prophetic parenting terhadap perbedaan skor prates, pascates 1 dan pascates 2 (Field, 2009). Uji tambahan menggunakan uji mann whitney untuk mengetahui perbedaan antara dua kelompok partisipan. Berikut hasil analisis penelitian:

Tabel 2.

Hasil Friedman test pada kelompok eksperimen

\begin{tabular}{ccccc}
\hline Variabel & Kelompok & Mean Rank & Sig. & Keterangan \\
\hline Prates & & 3.00 & & \\
Pascates1 & Eksperimen & 1.67 & 0.043 & Signifikan \\
Pascates2 & & 1.33 & & \\
\hline
\end{tabular}


Hasil dari friedman test menunjukkan bahwa nilai signifikansi $\mathrm{p}=0.043(\mathrm{p}<0.05)$. Artinya adalah ada perbedaan skor yang signifikan antara pengukuran prates, pascates 1 , dan pascates 2 setelah diberikannya pelatihan prophetic parenting pada kelompok eksperimen.

Tabel 3.

Hasil Uji Mann Whitney

\begin{tabular}{ccccc}
\hline Variabel & Kelompok & Mean Rank & Sig. & Keterangan \\
\hline \multirow{2}{*}{ Pascates 1} & Eksperimen & 2.50 & \multirow{2}{*}{0.054} & Tidak Signifikan \\
& Kontrol & 5.13 & & \\
Pascates 2 & Eksperimen & 2.00 & \multirow{2}{*}{0.017} & Signifikan \\
\hline
\end{tabular}

Hasil uji mann whitney menunjukkan bahwa nilai signifikansi saat pascates 1 adalah sebesar $\mathrm{p}=0.054(\mathrm{p}>0.05)$, artinya tidak ada perbedaan antara kelompok eksperimen dan kelompok kontrol. Adapun nilai signifikansi saat pascates 2 adalah sebesar $p=0.017$ $(\mathrm{p}<0.05)$, artinya ada perbedaan antara kelompok eksperimen dan kelompok kontrol ketika dilakukan pengukuran pascates 2 (tindak lanjut).

\section{Diskusi}

Tujuan dari penelitian ini adalah untuk mengetahui apakah ada pengaruh pelatihan prophetic parenting terhadap penurunan stres pengasuhan pada ibu dengan anak disabilitas tunanetra. Berdasarkan hasil dari penelitian yang telah dilakukan menunjukan bahwa pelatihan prophetic parenting dapat memberikan perubahan yang signifikan terhadap menurunnya stres pengasuhan pada ibu yang memiliki anak disabilitas tunanetra. Hal tersebut dibuktikan dengan adanya perbedaan yang signifikan antara hasil skor pada kelompok kontrol dengan kelompok eksperimen pada rentang waktu prates menuju pascates 2 .

Hasil penelitian ini mendukung dan membuktikan pernyataan bahwa prophetic parenting dapat membuat orangtua merasakan kebahagiaan, ketenangan baik di dalam hati ataupun pikiran, serta membantu orangtua dalam melakukan pengasuhan dan pendidikan anak untuk tumbuh dalam kebaikan (Suwaid, 2010). Dalam hal ini orangtua melakukan pengasuhan meneladani rosul secara tenang dan tidak terburu-buru, sehingga memerlukan waktu yang panjang dalam mempraktekannya (Suwaid, 2010).

Penelitian ini juga mendukung hasil penelitian sebelumnya yang telah dilakukan oleh Kurniawan dan Uyun (2013) bahwa pendidikan pengasuhan spiritualitas mampu menurunkan stres pengasuhan dan disfungsi interaksi orangtua. Penelitian lain dari Rahayu, Ni'matuzzahroh, dan Amalia (2019) juga menguatkan yakni religiusitas yang 
dimiliki orangtua sangat terkait dengan penurunan stres pengasuhan karena penghayatan terhadap nilai religius memunculkan perasaan-perasaan positif sehingga menjadikan orangtua dapat melakukan pengasuhan yang lebih positif. Selain itu, sejalan juga dengan penelitian dari Pamungkas (2015) yakni adanya penurunan stres pengasuhan karena diberikannya pelatihan keterampilan pengasuhan efektif pada ibu yang memiliki anak autis. Hal tersebut dapat terjadi salah satunya karena pendidikan pengasuhan yang mengacu pada pelatihan telah dirancang untuk memberikan pengetahuan dan mengajarkan keterampilan mengasuh pada orangtua (Schultz, Schmidt, \& Stichter, 2011).

Seperti yang dialami oleh para subjek, mengungkapkan bahwa ketiganya mendapatkan pengetahuan baru tentang pengasuhan, sudah mengetahui bagaimana menasihati anak dengan cara yang tepat. Sudah lebih dapat memahami bagaimana cara merespon anak spesial ketika mengalami emosi marah. Ketiganya juga berpendapat sama mengenai ketenangan yang dialami setelah mengikuti pelatihan prophetic parenting. Harapan terhadap masa depan anaknya pun saat ini cukup besar dan tertanam positif dalam diri para ibu. Sesuai dengan pernyataan dari para subjek, hasil dari pengukuran skala stres pengasuhan pun menunjukan bahwa aspek distres orangtua adalah aspek yang paling mengalami perubahan secara positif setelah dilakukannya pelatihan prophetic parenting.

Selain pengetahuan dan keterampilan pengasuhan yang disajikan dalam pelatihan ini, terdapat satu hal lagi yang membuat orangtua memiliki keyakinan yang besar dan merasa termotivasi akan tanggung jawabnya terhadap pengasuhan yang terbaik bagi anaknya, yaitu pelatihan ini menggunakan pendekatan spiritual. Pengasuhan ini menekankan bahwa anak adalah amanah dari Allah sehingga orangtua harus dapat mempertanggungjawabkan perilaku pengasuhan yang telah dilakukannya. Orangtua juga dijanjikan oleh Allah dalam al-qur'an bahwa setiap manusia tidak akan diberikan beban di luar kesanggupannya. Kedua pendapat tersebut mengacu pada hadits dan ayat al-qur'an sebagai berikut:

"Setiap kalian adalah pemimpin dan setiap kalian adalah orang yang dimintai pertanggungjawaban tentang orang-orang yang dipimpinnya. Laki-laki adalah pemimpin keluarganya, dia akan dimintai pertanggungjawaban tentang orang-orang yang dipimpinnya. Seorang perempuan adalah pemimpin di rumah suaminya, dia akan dimintai tanggungjawab tentang orang-orang yang dipimpinnya. Seorang pelayan adalah pemimpin harta tuannya. Dia akan dimintai pertanggung jawaban atas harta 
yang dia urus. Maka tiap-tiap kamu adalah pemimpin dan tiap-tiap kamu akan ditanya kepemimpinannya" (H.R. Al-Bukhari 893 dan Muslim 1829)

“Seseorang tidak dibebani melainkan menurut kadar kesanggupannya..."(Q.S. AL Baqarah: 286)

Pandangan orangtua terhadap pernyataan bahwa anak merupakan amanah bagi setiap orangtua yang memilikinya juga mampu memotivasi subjek dalam menjalankan pengasuhan sebagai sarana beribadah kepada Allah. Sesuai dengan yang diungkapkan oleh subjek penelitian yaitu PL, AY, dan S yang saat ini menyadari bahwasannya meskipun kondisi anak mereka tidak seperti anak lain pada umumnya namun ketiganya memiliki tekad untuk berusaha melakukan pengasuhan yang lebih baik.

Sejalan dengan hal tersebut Kurniawan dan Uyun (2013) mengatakan bahwa orangtua yang mampu memaknai aspek kehidupan dengan spiritual dapat memunculkan emosi-emosi seperti perasaan bersyukur, ketakjuban, rendah hati, keyakinan, dan harapan tentang kehidupan anak. Hal tersebut sesuai juga dengan yang diungkapkan oleh para subjek. Ketiga subjek menyatakan bahwa seperti memiliki harapan baru tentang masa depan anak-anaknya. Rasa bersyukur yang membuat ketiganya mampu mengenali dan menyadari bahwa masing-masing anaknya memiliki potensi atau hal positif yang dapat dikembangkan.

Sebelum ketiga subjek dapat mengungkapkan hal-hal positif yang terdapat pada anaknya, masing-masing subjek mengaku bahwa diri mereka merasa sedih, khawatir, dan tidak tenang ketika mendapatkan anak yang memiliki keterbatasan penglihatan, namun setelah mengikuti pelatihan AY, PL, dan S mengaku lebih tenang sehingga memiliki kesabaran yang lebih besar ketika menghadapi permasalahan pengasuhan. Sejalan dengan pendapat dari Chang, Noonan, dan Tennstedt (1998) yaitu spiritualitas yang disajikan oleh prophetic parenting dapat menjadi salah satu komponen penting dalam mengatasi permasalahan melalui hubungan yang baik antara orangtua dan anak, orangtua dapat memberikan perhatian dan rasa aman serta nyaman pada diri anak. Didukung oleh pernyataan dari Bashir, Khurid, dan Qardi (2014) yakni keyakinan spiritualitas mampu membawa perubahan positif untuk lebih termotivasi mengatasi tantangan pengasuhan anak disabilitas.

Penelitian yang dilakukan oleh Murray-Swank, Mahoney, dan Pargament (2006) menunjukan bahwa orangtua yang memandang pengasuhan sebagai salah satu bentuk ibadah kepada Allah dapat meningkatkan hubungan yang positif dan hangat terhadap anak. Orangtua yang percaya bahwa pengasuhan merupakan sebuah tanggung jawab 
dapat mendorong mereka untuk melakukan praktik pengasuhan yang positif dan lebih konsisten, mengasuh dengan hati nurani dan kasih sayang, juga menghindari kekerasan verbal (Murray-Swank, Mahoney, dan Pargament 2006; Ellison \& Bradshaw, 2009). Berkaitan dengan hal tersebut terdapat penelitian yang dilakukan oleh Gani dan Kumalasari (2019) bahwa stres pengasuhan dapat berkurang ketika terjadinya komunikasi yang baik antara orangtua dan anak, adanya penerapan disiplin yang konsisten.

Jika dilihat prakteknya dari para subjek penelitian ini, para orangtua secara sedikit demi sedikit mencoba menerapkan rutin mengajak anaknya mengobrol ketika sedang bersantai kemudian ketika anak dari masing-masing subjek melakukan hal positif, para subjek mulai merespon dengan memberikan apresiasi terhadap perilaku yang dilakukan anak. Dampak yang subjek rasakan setelah mengikuti pelatihan dan mencoba menerapkannya adalah subjek merasa bisa lebih sabar dan tenang terhadap segala perilaku yang dilakukan oleh anaknya. Dari semua hal yang disampaikan para subjek, dapat dikatakan bahwa pengasuhan prophetic parenting diterapkan oleh ibu secara bertahap, penuh kesabaran, dan mencobanya secara rutin. Oleh karena itu proses penerapan metode-metode dari prophetic parenting membutuhkan waktu. Hal tersebut karena pengasuhan sangat terkait dengan memperbaiki interaksi orangtua-anak, dan pribadi anak yang sulit.

Adapun pernyataan dari Rasulullah shalallahu 'alaihi wa sallam yang sejalan dengan pemaparan sebelumnya yakni prophetic parenting memerlukan penerapan yang bertahap, dilakukan dengan kesabaran, kelembutan dan sedikit demi sedikit (Suwaid, 2010). Hal itu dibuktikan dengan hasil analisis kuantitatif yang menunjukkan bahwa aspek parent-child dysfunctional mengalami perubahan yang signifikan menuju ke arah yang lebih positif saat dilakukan pengukuran tindak lanjut yakni dua pekan setelah pelatihan selesai. Pernyataan tersebut memiliki arti bahwa para subjek memerlukan waktu dalam menerapkan prophetic parenting hingga perubahan positif terhadap aspek parent-child dysfunctional dapat dirasakan oleh subjek dan keluarga.

Berdasarkan pemaparan di atas, dapat disimpulkan bahwa pelatihan prophetic parenting memberikan pengaruh yang signifikan terhadap menurunnya stres pengasuhan pada subjek kelompok eksperimen. Hal ini didukung juga oleh data hasil wawancara yakni ketiga subjek pada kelompok eksperimen merasakan perubahan dan manfaat yang positif dari segi emosi, pikiran, perilaku, dan spiritual kaitannya dengan pengasuhan yang dilakukan setelah mengikuti pelatihan prophetic parenting. 


\section{Simpulan}

Pelatihan prophetic parenting pada penelitian ini memberikan perubahan yang signifikan terhadap menurunnya stres pengasuhan pada ibu dengan anak disabilitas tunanetra. Hal tersebut didukung juga oleh analisis kualitatif yakni ketiga subjek merasakan perubahan dan manfaat yang positif setelah mengikuti pelatihan prophetic parenting baik dari segi emosi, pikiran, perilaku, dan spiritual yang kaitannya dengan pengasuhan.

\section{Saran}

Subjek Penelitian. Subjek diharapkan dapat ajeg menerapkan materi yang diperoleh selama mengikuti pelatihan prophetic parenting dalam kehidupan sehari-hari. Salah satunya adalah dengan meyakini bahwa mengasuh anak merupakan amanah dari Allah sehingga ketika melakukan pengasuhan akan selalu memberikan yang terbaik, dan menerima kondisi anak sebagai ketetapan dari Allah. Pentingnya menerapkan prophetic parenting adalah agar terjadinya proses pengasuhan yang positif sehingga dapat meminimalkan stres pengasuhan. Subjek juga diharapkan dapat berbagi materi yang telah didapatkan kepada suami masing-masing sehingga keterlibatan kedua orangtua dapat bersinergi untuk pengasuhan yang lebih baik terhadap anak.

Pihak Sekolah. Pihak sekolah diharapkan dapat mengadakan pertemuan rutin antara walimurid dengan agenda psikoedukasi atau pelatihan pengasuhan anak dengan disabilitas agar orangtua dapat menambah wawasan, saling memberikan dukungan, dan berbagi solusi dalam menghadapi tantangan dalam pengasuhan.

Penelitian Selanjutnya. Penelitian selanjutnya dapat mengontrol data demografik. Kemudian peneliti dapat melibatkan ayah atau pasangan subjek dalam pelatihan pengasuhan. Terakhir terkait dengan pelaksanaan penelitian dapat dilakukan jeda antar pertemuannya agar subjek memiliki waktu untuk dapat mempraktikkan prophetic parenting.

\section{Kepustakaan}

Ahern, L. S. (2004). Psychomentric properties of the parenting stress index - short form. Ethesis.

Bashir, A. Khursid, A., \& Qadri, F. (2014). Wareness and Problems of Parents of Children with Autism Spectrum Disorders. International Journal of Interdisciplinary Research and Innovations, 2(2), 42-48.

Chang, M., \& McConkey, R. (2008). The perceptions and experiences of Taiwanese Parents who have children with an intellectual disability. International Journal of Disability, Developmental Review, 18, 47-85.

Cook, T. D. \& Campbell, D. T. (1979). Quasi-Experimentation: Design \& Analysis Issues for Field Settings. USA: Houghton Mifflin Company. 
Deater-Deckard, K. (1998). Parenting stress and child adjustment: Some old hypotheses and new questions. American Psychological Association, 5(3), 314-332. https://doi.org/10.1111/j.1468-2850.1998.tb00152.x

Desiningrum, D. R. (2016). Psikologi anak berkebutuhan khusus. Yogyakarta: Psikosain.

Edi, R. N. (2014). As-sunnah (hadits): suatu kajian aliran ingkar sunnah. Asas, 6(2), 132148.

Ellison C. G. Bradshaw, M. (2006). Religious beliefs, sociopolotical ideology, and attitudes toward corporal punishment. Journal Family Issues, 30, 320-340. DOI: 10.1177/0192513X08326331.

Field, A. (2009). Discovering statistics using spss. London: Sage Publications Ltd.

Fitria, B. (2018). Pelatihan prophetic parenting untuk meningkatkan resiliensi pada orang tua dengan anak penyandang disabilitas. (Tesis tidak dipublikasikan). Fakultas Psikologi dan Ilmu Sosial Budaya Universitas Islam Indonesia, Yogyakarta.

Gani, I. A. A. \& Kumalasari, D. (2019). Be mindful, less stress: studi tentang mindful parenting dan stres pengasuhan pada ibu dari anak usia middle childhood di jakarta. Jurnal Psikologi, 15(2), 98-107.

Hsiao, Y. J. (2017). Parental stress in families of children with disabilities. Intervention in Schiil and Clinic, 00(0), 1-5. DOI:10.1177/1053451217712956.

Jabbarifar, S. E., Ahmady, N., Sahafian, S. A. R., Samei, F. \& Soheillipour, S. (2009). Association of parental stress and early childhood caries. Dental research Journal, 6(2), 65-70.

Kamaruddin. (2019). Bimbingan karir terhadap anak tunanetra: Studi kasus di sekolah luar biasa negeri pinrang. Indonesian Journal of Islamic Counseling (IJIC), 1(1), 5676.

Kurniawan, I. N. (2012). Potraying parenting-stress of Indonesian parents with parenting stress index-short form: A Premliminery Study, Research Report. Yogyakarta: Child and Family Study Centre.

Kurniawan, I. N. \& Uyun, Q. (2013). Penurunan stres pengasuhan orang tua dan disfungsi interaksi orang tua-anak melalui pendidikan pengasuhan versi pendekatan spiritual (PP-VPS). Jurnal Intervensi Psikologi, 5(1), 110-130.

Murray-Swank, N. A., Mahoney, A.,, \& Pargament, K. I. (2006). Sanctification of parenting: Influences on corporal punishment and warmth by liberal and conservatife christian mothers. The International Journal of the Psychology of Religion, 16, 271287.

Nashori, H.F., Diana, R.R., \& Hidayat, B. (2020). The trend in Islamic Psychology Intervension in Indonesia. Research in the Social Scientific Study of Religion, 20, 162-180.

Omnihara, H. W., Marapaung, W., \& Mirza, R. (2019). Kepercayaan diri ditinjau dari dukungan sosial pada penyandang tunanetra. Psycho Idea, 17(2), 114-122. ISSN 2654-3516.

Pamungkas, A. (2015). Pelatihan keterampilan pengasuhan autis untuk menurunkan stres pengasuhan pada ibu dengan anak autis. Jurnal Empathy, 3(1), 1-22.

Pemerintah Indonesia. (2014). Undang-Undang Republik Indonesia nomor 35 tahun 2014 tentang perubahan atas undang-undang nomor 23 tahun 2002 tentang perlindungan anak. Jakarta: Sekretariat Negara.

Quinonez, R. B., Keelsc, M. A., Jr. Vann, W. F., Mclver, F. T. Heller, K, \& Whitt, J. K. (2001). Early childhood caries: analysis of psychosocial and biological factors in a highrisk population. Caries Research, 35, 376-383.

Rahayu, A. T. D., Ni'matuzzahroh, \& Amalia, S. (2019). Religiusitas dan stres pengasuhan pad ibu dengan anak autis. Jurnal Ilmiah Psikologi Terapanl,07(02). pISSN: 23018267 / eISSN: 2540-829. 
ISSN 2580-6076 (Print), ISSN 2580-8532 (Online)

Schultz, T. R., Schmidt, C. T., \& Stichter, J. P. (2011). A review of parents education programs for parent of children with autism spectrum disorders. Focus on Autism and Other Developmental Disabilities, 26, 96-104. DOI: 10.1177/1088357610397346.

Suwaid, M. N. A. H. (2010). Prphetic parenting: Cara nabi SAW mendidik anak. Yogyakarta: Pro-U Media.

Thwala, S. K., Ntinda, K., \& Hlanze, B. (2015). Lived experiences of parents' of children with disabilites in swaziland. Journal of Education and Training Studies, 3(4).

Uswatunnisa, A., Brebahama, A., \& Kinanthi, M. R. (2018). Resiliensi keluarga yang memiliki anak tunanetra. Jurnal of Psychological Research SCHEMA, 4(2), 88-97.

Williford, A. P., Calkins, S.D., \& Keane, S.P. (2007). Predicting change in parenting stress across early childhood: Child and maternal factors. Journal of Abnormal Child Psychology, 35, 251-263. 